\title{
An Analytical Study on Dynamic Response of Multiple Simply Supported Beam System Subjected to Moving Loads
}

\author{
Zhipeng Lai $\mathbb{D}^{1},{ }^{1}$ Lizhong Jiang, ${ }^{1,2}$ and Wangbao Zhou $\mathbb{D}^{1,2}$ \\ ${ }^{1}$ School of Civil Engineering, Central South University, Changsha 410075, China \\ ${ }^{2}$ National Engineering Laboratory for High Speed Railway Construction, Changsha 410075, China \\ Correspondence should be addressed to Wangbao Zhou; zhouwangbao@163.com
}

Received 22 March 2018; Revised 13 June 2018; Accepted 26 June 2018; Published 9 July 2018

Academic Editor: Sundararajan Natarajan

Copyright ( 2018 Zhipeng Lai et al. This is an open access article distributed under the Creative Commons Attribution License, which permits unrestricted use, distribution, and reproduction in any medium, provided the original work is properly cited.

\begin{abstract}
Based on Euler-Bernoulli beam theory, first, partial differential equations were established for the vibration of multiple simply supported beams subjected to moving loads. Then, integral transforms were conducted on the spatial displacement coordinate and time in the partial differential equations, and the frequency-domain response of multiple simply supported beams subjected to moving loads was obtained. Next, by conducting the corresponding inverse transforms on the displacement frequency-domain responses of multiple simply supported beams, the spatial displacement time-domain responses were obtained. Finally, to validate the analytical method reported in this paper, the dynamic response of a typical double simply supported rail-bridge beam system of high-speed railway in China subjected to a moving load was carried out. The results show that the analytical solution proposed in this paper is consistent with the results obtained from a finite element analysis, validating and rationalizing the analytical solution. Moreover, the system parameters were analyzed for the dynamic response of double simply supported rail-bridge beam system in high-speed railway subjected to a moving load with different speeds; the conclusions can be beneficial for engineering practice.
\end{abstract}

\section{Introduction}

Moving-load dynamic problems are very common in engineering and daily life [1] and have attracted much attention for decades and recently raised many engineering concerns such as the traffic comfort and safety of high-speed railway lines and new materials for mechanical and aerospace engineering. The problem of dynamic response of a structure subjected to moving loads has always been the focus in engineering practice.

For decades, the dynamic response of a single beam has been extensively investigated. Many previous studies have provided better solutions to this problem [2-6], and there are also many papers on beam vibration excited by a moving mass [7-10]. In the recent decades, much effort has been devoted to the analysis of dynamic response of a double-beam system, and the results are significant [11-16].

The free and forced vibration analyses of a double-beam system have been extensively investigated. ONISZCZUK [17, 18] reported the free vibration analysis of two parallel simply supported beams continuously joined by a Winkler elastic layer. Zhang [19] investigated the vibration and buckling of a double-beam system with identical elastic modulus under compressive axial loading on the basis of Euler-Bernoulli beam theory. The properties of free transverse vibration of the system significantly depended on the axial compressions. Similarly, Stojanović [20] studied the forced vibration and buckling of a Rayleigh and Timoshenko double-beam system continuously joined by a Winkler elastic layer under compressive axial loading, while the elastic modulus of double beam was also the same. Palmeri [21] proposed a Galerkintype state-space approach for the transverse vibrations of slender double-beam systems joined with a viscoelastic inner layer and conducted numerical applications on modal shapes, modal frequencies, and forced vibrations. Zhang [22] investigated the transverse vibration of two parallel Timoshenko beams connected by discrete springs and coupled with discontinuities by considering both free and forced vibration. $\mathrm{Li}$ and $\mathrm{Hu}[23]$ developed a semianalytical method to investigate the natural frequencies and mode shapes of a doublebeam system interconnected by a viscoelastic layer, while the modal-expansion iterated method was further applied 
to determine the forced vibration responses of the doublebeam system. Abu-Hilal studied the dynamic response of a double-beam system traversed by a constant moving load [24]. Although the dynamic deflections of both beams were provided in analytical closed forms, the two simply supported prismatic beams should be identical. Unlike Abu-Hilal's research, $\mathrm{Wu}$ [25] investigated the dynamic response of a simply supported viscously damped double-beam system under moving harmonic loads; the double-beam system consisted of two finite elastic homogeneous isotropic beams, which were also identical, parallel, and connected continuously by a layer of elastic springs with viscous damping. Meanwhile, based on the double-beam theory the dynamic characteristics of a railway system have been investigated [26-29].

The dynamic responses of a triple-beam system have also intrigued many scholars' attention. Stojanović studied the stochastic stability of three elastically connected Euler beams on an elastic foundation using a perturbation approach [30]. Li developed a dynamic stiffness method for a general elastically connected three-beam system based on both Euler-Bernoulli beam theory [31] and Timoshenko beam theory [32]. A dynamic stiffness matrix was formulated from the analytical closed-form solutions of differential equations of motion of the three-beam element in free transverse vibration and then used along with the automated Muller root search algorithm to calculate the free vibration characteristics of three-beam system.

Increasing efforts have also been devoted to analyze the dynamic responses of a multiple-beam system. Rao [33] investigated the natural vibrations of elastically connected multi-Timoshenko beams. Mao [34] used the Adomian modified decomposition method (AMDM) to investigate the free vibrations of $\mathrm{N}$ elastically connected parallel Euler-Bernoulli beams continuously joined by a Winkler-type elastic layer, and a general solution for the free vibration problem of elastically connected beams under general boundary conditions was obtained. Stojanović developed a general procedure for the determination of natural frequencies and buckling load for a set of beam system under compressive axial load using Timoshenko and high-order shear deformation theory [35]. The set of beams were simply supported and continuously joined by a Winkler elastic layer. Kargarnovin [36] proposed a closed-form solution to study the dynamics of a composite beam with a single delamination under the action of a moving constant force; the delaminated beam was divided into four interconnected beams using the delamination limits as their boundaries. Ariaei [37] investigated the transverse dynamic response of an elastically connected multiple beam based on Timoshenko beam theory, involving a change in variables and modal analysis to decouple and solve the governing differential equations, respectively. However, the parallel beams were assumed to be identical and connected by a finite number of springs.

These studies indicate that although the moving loads problem on beam-like structure has been investigated profoundly in a way, studies on the dynamic response of a beam mainly focused on single-beam and double-beam models, and many studies have some limitations. For example, the materials and geometric properties of each beam are required to be identical, the analytic expression forms are too complex to be extended to multiple beams, and studies are lacking on the dynamic response of multiple beams with different properties subjected to moving loads. Therefore, the dynamic responses of a multiple simply supported Euler-Bernoulli beam system with elastic connection were evaluated in this study; combined with finite sin-Fourier transform and numerical Laplace transform based on Durbin transform, the spatial displacement time-domain response of a multiple simply supported beam system was obtained. Then, an analytical method developed in this study was used to calculate the dynamic response of a rail-bridge double simply supported beam system of a high-speed railway system in China subjected to a moving load, validating and rationalizing the analytical solution reported in this paper, drawing some conclusions meaningful to engineering design, and thus laying foundations for further applications of the multiple simply supported beam system in engineering.

\section{Model of a Multiple Simply Supported Beam System Subjected to Moving Loads}

The N-layer simply supported beam system is shown in Figure 1. The length of each beam is L; the beams are connected vertically through springs evenly distributed along the beam length. Based on Euler-Bernoulli beam theory, according to the dynamic equilibrium relationship of the multiple simply supported beam system subjected to moving loads, the corresponding partial differential equations for the vibration of the system can be established as follows:

$$
\begin{aligned}
& m_{1} \frac{\partial^{2} u_{1}(x, t)}{\partial t^{2}}+E_{1} I_{1} \frac{\partial^{4} u_{1}(x, t)}{\partial x^{4}} \\
& \quad+k_{1}\left(u_{1}-u_{2}\right)=\delta(x-v t) P_{1}(t) \\
& m_{r} \frac{\partial^{2} u_{r}(x, t)}{\partial t^{2}}+E_{r} I_{r} \frac{\partial^{4} u_{r}(x, t)}{\partial x^{4}} \\
& \quad-k_{r-1}\left[u_{r-1}(x, t)-u_{r}(x, t)\right] \\
& \quad+k_{r}\left[u_{r}(x, t)-u_{r+1}(x, t)\right]=\delta(x-v t) P_{r}(t) \\
& m_{N} \frac{\partial^{2} u_{N}(x, t)}{\partial t^{2}}+E_{N} I_{N} \frac{\partial^{4} u_{N}(x, t)}{\partial x^{4}} \\
& \quad-k_{N-1}\left[u_{N-1}(x, t)-u_{N}(x, t)\right]=\delta(x-v t) P_{N}(t)
\end{aligned}
$$

where $\mathrm{m}_{r}$ is the mass per unit length of the $r$ th simply supported beam, $\mathrm{E}_{r}$ and $\mathrm{I}_{r}$ are the elasticity modulus and horizontal inertia moment of the $r$ th simply supported beam, respectively, and $\mathrm{u}_{r}(x, t)$ is the vertical displacement response of the $r$ th simply supported beam; $\mathrm{P}_{1}(t) \sim \mathrm{P}_{N}(t)$ are the external loads on the multiple simply supported beam system, $\mathrm{k}_{r}$ is the spring stiffness between the $r$ th and $r+1$ th simply supported beams, $v$ is the moving speed of external loads, and $\delta$ is Dirac function.

To solve the partial differential equations (1)-(3) of the system, integral transform methods were used in this paper. First, finite sin-Fourier Transform was conducted on spatial 


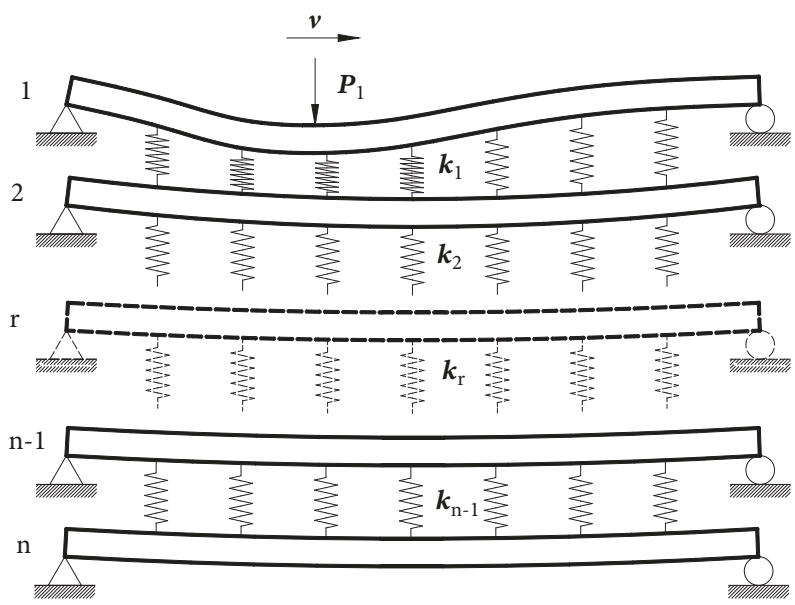

FIGURE 1: Model of a multiple simply supported beam system.

coordinate $x$. Regarding $0 \leq x \leq \mathrm{L}$, the transform can be defined as follows [38]:

$$
\begin{aligned}
F[u(x)] & =\widetilde{u}\left(\xi_{k}\right)=\int_{0}^{L} u(x) \sin \left(\xi_{k} x\right) d x \\
F^{-1}\left[\widetilde{u}\left(\xi_{k}\right)\right] & =u(x)=\frac{2}{L} \sum_{k=1}^{\infty} \widetilde{u}\left(\xi_{k}\right) \sin \left(\xi_{k} x\right)
\end{aligned}
$$

where

$$
\xi_{k}=\frac{k \pi}{L}, \quad k=1,2,3, \ldots
$$

Based on (4), finite sin-Fourier transform was conducted on $u^{(4)}(x)$, the quartic derivative of displacement function with respect to $x$, and the following expression was obtained:

$$
\begin{aligned}
F\left\{\frac{\mathrm{d}^{4} u(x)}{\mathrm{d} x^{2}}\right\}= & -\xi_{k} u^{\prime \prime}(L)(-1)^{k}+\xi_{k} u^{\prime \prime}(0)+\xi_{k}^{4} \widetilde{u}\left(\xi_{k}\right) \\
& -\xi_{k}^{3} u(0)+(-1)^{k} \xi_{k}^{3} u(L)
\end{aligned}
$$

Considering a small deformation, the boundary condition for the simply supported beam can be described as follows:

$$
\begin{array}{r}
\left.u(x, t)\right|_{x=0}=0, \\
\left.\operatorname{EIu}^{\prime \prime}(x, t)\right|_{x=0}=0 \\
\left.u(x, t)\right|_{x=L}=0, \\
\left.\operatorname{EIu}^{\prime \prime}(x, t)\right|_{x=L}=0
\end{array}
$$

According to the boundary conditions in (8), (7) can be simplified as follows:

$$
F\left\{\frac{\partial^{4} u(x, t)}{\partial x^{4}}\right\}=\xi_{k}^{4} \widetilde{u}\left(\xi_{k}, t\right)
$$

Finite sin-Fourier transform with regard to spatial coordinate $x$ was conducted on the left and right sides of (1)-(3), and the following equations can be obtained:

$$
\begin{aligned}
& m_{1} \frac{\partial^{2} \widetilde{u}_{1}\left(\xi_{k}, t\right)}{\partial t^{2}}+E_{1} I_{1} \xi_{k}^{4} \widetilde{u}_{1}\left(\xi_{k}, t\right) \\
& \quad+k_{1}\left[\widetilde{u}_{1}\left(\xi_{k}, t\right)-\widetilde{u}_{2}\left(\xi_{k}, t\right)\right]=P_{1}(t) \sin \left(\xi_{k} v t\right) \\
& m_{r} \frac{\partial^{2} \widetilde{u}_{r}\left(\xi_{k}, t\right)}{\partial t^{2}}+E_{r} I_{r} \xi_{k}^{4} \widetilde{u}_{r}\left(\xi_{k}, t\right) \\
& \quad-k_{r-1}\left[\widetilde{u}_{r-1}\left(\xi_{k}, t\right)-\widetilde{u}_{r}\left(\xi_{k}, t\right)\right] \\
& \quad+k_{r}\left[\widetilde{u}_{r}\left(\xi_{k}, t\right)-\widetilde{u}_{r+1}\left(\xi_{k}, t\right)\right]=P_{r}(t) \sin \left(\xi_{k} v t\right) \\
& m_{N} \frac{\partial^{2} \widetilde{u}_{N}\left(\xi_{k}, t\right)}{\partial t^{2}}+E_{N} I_{N} \xi_{k}^{4} \widetilde{u}_{N}\left(\xi_{k}, t\right) \\
& \quad-\left[k_{N-1}\left[\tilde{u}_{N-1}\left(\xi_{k}, t\right)-\tilde{u}_{N}\left(\xi_{k}, t\right)\right]\right] \\
& \quad=P_{N}(t) \sin \left(\xi_{k} v t\right)
\end{aligned}
$$
form,

According to the derivative theorem of Laplace trans-

$$
L\left\{\frac{\mathrm{d}^{2} u(t)}{\mathrm{d} t^{2}}\right\}=s^{2} u^{*}(s)-s u^{\prime}\left(0^{+}\right)-u\left(0^{+}\right)
$$

where $s$ is the transformed variable corresponding to time $t$.

The initial conditions of multiple simply supported beam system can be defined as follows:

$$
\begin{aligned}
& u_{i}(x, 0)=0, \\
& \dot{u}_{i}(x, 0)=0,
\end{aligned}
$$

From (13) and (14), Laplace transformation on the second derivative of displacement responses of simply supported beam system with respect to time can be obtained as follows:

$$
L\left\{\frac{\partial^{2} u_{i}(x, t)}{\partial t^{2}}\right\}=s^{2} u_{i}^{*}(x, s), \quad i=1, \ldots \mathrm{r} \ldots, N
$$


Laplace transformation with respect to time $t$ was conducted on the left and right sides of (10)-(12), and the following equations can be obtained after reorganizing and combining similar terms:

$$
\begin{aligned}
& \left(m_{1} s^{2}+k_{1}+E_{1} I_{1} \xi_{k}^{4}\right) \tilde{u}_{1}^{*}\left(\xi_{k}, s\right)-k_{1} \widetilde{u}_{2}^{*}\left(\xi_{k}, s\right) \\
& \quad=C_{1}\left(\xi_{k}, s\right) \\
& -k_{r-1} \widetilde{u}_{r-1}^{*}\left(\xi_{k}, s\right) \\
& \quad+\left[m_{r} s^{2}+E_{r} I_{r} \xi_{k}^{4}+k_{r-1}+k_{r}\right] \widetilde{u}_{r}^{*}\left(\xi_{k}, s\right) \\
& \quad-k_{r} \widetilde{u}_{r+1}^{*}\left(\xi_{k}, s\right)=C_{r}\left(\xi_{k}, s\right) \\
& -k_{N-1} \widetilde{u}_{N-1}^{*}\left(\xi_{k}, s\right) \\
& \quad+\left(m_{N} s^{2}+E_{N} I_{N} \xi_{k}^{4}+k_{N-1}\right) \widetilde{u}_{N}^{*}\left(\xi_{k}, s\right) \\
& \quad=C_{N}\left(\xi_{k}, s\right)
\end{aligned}
$$

where $C_{i}\left(\xi_{k}, s\right)=L\left[P_{i}(t) \sin \left(\xi_{k} v t\right)\right]$ is the external load of frequency domain on the $i$ th simply supported beam. The vector quantities for the frequency-domain responses and external loads of frequency domain on each simply supported beam can be denoted as follows:

$$
\begin{aligned}
& \left\{\widetilde{\mathbf{u}}^{*}\left(\xi_{k}, s\right)\right\} \\
& \quad=\left\{\widetilde{u}_{1}^{*}\left(\xi_{k}, s\right), \ldots, \tilde{u}_{r}^{*}\left(\xi_{k}, s\right), \ldots, \widetilde{u}_{N}^{*}\left(\xi_{k}, s\right)\right\}^{\mathrm{T}} \\
& \left\{\mathbf{C}\left(\xi_{k}, s\right)\right\} \\
& \quad=\left\{C_{1}\left(\xi_{k}, s\right), \ldots, C_{r}\left(\xi_{k}, s\right), \ldots, C_{N}\left(\xi_{k}, s\right)\right\}^{\mathrm{T}}
\end{aligned}
$$

Therefore, (16)-(18) can be expressed as follows:

$$
[\mathrm{D}]\left\{\widetilde{\mathbf{u}}^{*}\left(\xi_{k}, s\right)\right\}=\left\{\mathbf{C}\left(\xi_{k}, s\right)\right\}
$$

where $\mathbf{D}$ is the matrix with respect to $N \times N$, and only the following elements are nonzero:

$$
\begin{aligned}
D_{11} & =m_{1} s^{2}+E_{1} I_{1} \xi_{k}^{4}+k_{1}, \\
D_{r-1 r} & =D_{r r-1} \\
D_{r r} & =m_{r} s^{2}+E_{r} I_{r} \xi_{k}^{4}+k_{r-1}+k_{r}, \\
D_{r r-1} & =-k_{r-1}, \\
D_{r r+1} & =-k_{r} \\
D_{N N} & =m_{N} s^{2}+E_{N} I_{N} \xi_{k}^{4}+k_{N-1}, \\
D_{r+1 r} & =D_{r r+1}
\end{aligned}
$$

The frequency-domain responses $\left\{\widetilde{\mathbf{u}}^{*}\left(\xi_{k}, s\right)\right\}$ for each beam in the multiple simply supported beam system can be obtained by solving the linear algebraic equation (21). Finite sin-Fourier inverse transformation was conducted on the frequency-domain responses $\left\{\widetilde{\mathbf{u}}^{*}\left(\xi_{k}, s\right)\right\}$ for the multiple simply supported beam system, and the spatial displacement responses for the multiple simply supported beam system with respect to the time-frequency domains can be obtained as follows:

$$
u_{i}(x, s)=\sum_{k=1}^{M} \tilde{u}_{i}^{*}\left(\xi_{k}, s\right) \sin \left(\xi_{k} x\right) d x
$$

$$
i=1, \ldots \mathrm{r} \ldots, N
$$

Laplace inverse transform (LIT) with respect to timefrequency domain $s$ was conducted on the left and right sides of (25), and the spatial displacement time-domain responses for the multiple simply supported beam system can be obtained as follows:

$$
u_{i}(x, t)=L^{-1}\left[u_{i}(x, s)\right], \quad i=1, \ldots \mathrm{r} \ldots, N
$$

The solving process in this paper shows that the displacement frequency-domain response function $u_{i}(x, s)$ for each beam contains the product of power function and sine function. However, with the increase in the number of layers of simply supported beam, the analytical expression of (26) becomes complex and lengthy, and it is not easy to conduct an analytical expression on it. Therefore, to effectively solve the LIT for (26) according to arbitrary numbers of beams, fast LIT (FLIT) [39] proposed by Durbin was introduced in this paper to obtain the solution. This method of numerical inverse transform can be used to solve the transform results relatively accurately. It was verified that the error boundary of this method can be set to be any arbitrarily small value, so that better computing results can be obtained even for complex expressions. The corresponding solving programs are compiled in MATLAB to solve (21)-(26), and the spatial displacement time-domain response of different simply supported beam systems with arbitrary numbers of beams subjected to moving loads can be obtained.

\section{Analysis of Numerical Examples}

3.1. Validation of the Analytical Model. In the first place, as an application example of a double simply supported beam system subjected to moving loads, a typical rail-bridge system of high-speed railway system in China was selected for analysis. In this system, the first simply supported beam is a rail of ballastless tracks, and the second simply supported beam is a typical simply supported bridge with a span of $32 \mathrm{~m}$. The moving load acts on the first simply supported beam, and the materials of the double simply supported beam system and geometric parameters are shown as follows:

$$
\begin{aligned}
\mathrm{m}_{1} & =60 \mathrm{Kg} / \mathrm{m}, \\
\mathrm{E}_{1} & =2.1 \times 10^{5} \mathrm{Mpa}, \\
\mathrm{I}_{1} & =3.217 \times 10^{-5} \mathrm{~m}^{4} \\
\mathrm{~m}_{2} & =18.3 \times 10^{3} \mathrm{Kg} / \mathrm{m}, \\
\mathrm{E}_{2} & =3.45 \times 10^{4} \mathrm{Mpa},
\end{aligned}
$$




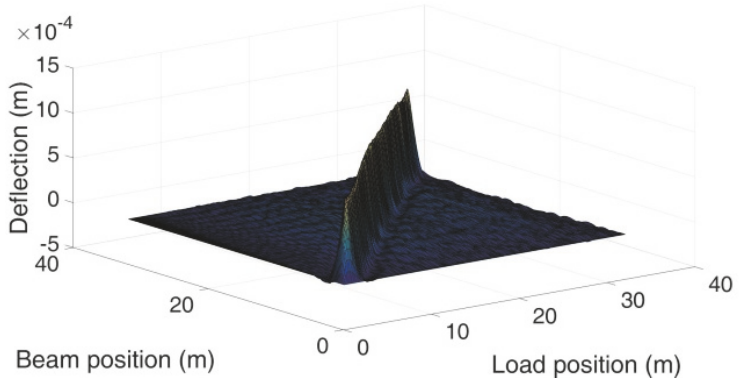

(a)

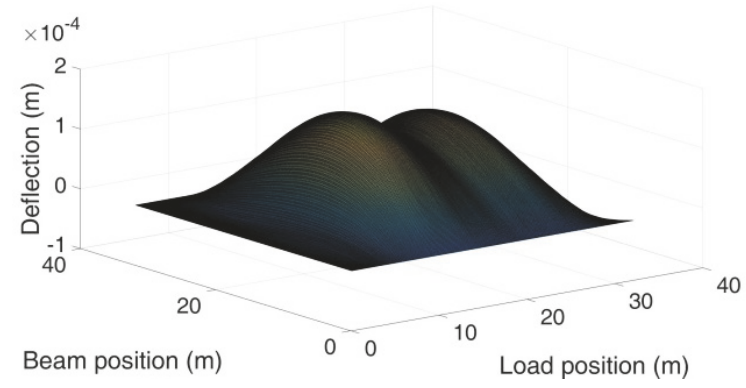

(b)

Figure 2: Deflections of double simply supported rail-bridge system with different positions of the moving load: (a) first beam; (b) second beam.

$$
\begin{aligned}
& \mathrm{I}_{2}=10.95 \mathrm{~m}^{4}, \\
& \mathrm{~L}_{1}=\mathrm{L}_{2}=32 \mathrm{~m}, \\
& \mathrm{k}_{1}=60 \mathrm{MN} / \mathrm{m}^{2}, \\
& \mathrm{p}_{1}=85 \mathrm{KN} .
\end{aligned}
$$

Based on the solving programs compiled in MATLAB, the vertical deflection of rail and bridge with different positions of the moving load in the double simply supported rail-bridge system when the moving speed of external load $\mathrm{v}=100 \mathrm{~m} / \mathrm{s}$ were plotted, as shown in Figure 2.

The results in the diagram show that the dynamic vertical deflection values for the rail and bridge in the double simply supported system subjected to moving loads reached the maximum near the mid-span (middle point of the system). The displacement time-history responses of the mid-span of first and second simply supported beams effectively reflect the maximum displacement responses of the double simply supported beam system of rail-bridge in a high-speed railway system. Hence, for the following computational analysis, the mid-span displacement responses for the double simply supported beam system were selected for analysis.

To validate the theoretical solution in this paper, ANSYS finite element software was used to conduct numerical simulation on the dynamic response of the double simply supported rail-bridge system subjected to moving loads, and the time-history responses for the mid-span displacements of the double simply supported rail-bridge system subjected to external load with different moving speeds $(32 \mathrm{~m} / \mathrm{s}$ and 64 $\mathrm{m} / \mathrm{s}$ ) were calculated. Regarding the FE model, the springs were modeled by Combin14 element in ANSYS, and the spacing between the Combin14 elements was set as $0.1 \mathrm{~m}$, which is a relatively small spacing, to model the continuous support between both the beams. Then, the results were compared with the theoretically calculated results, and the comparison results are shown in Figures 3 and 4. The results show that the theoretically calculated values are consistent with the results obtained from the ANSYS finite element numerical calculation.
Next, as another validation of the theoretical solution in this paper, the dynamic responses of a quadruple beam system subjected to moving loads were calculated by theoretical analysis model, and compared with the calculation results of ANSYS finite element software. The material and geometric parameters of the quadruple simply supported beam system are as follows:

$$
\begin{aligned}
\mathrm{m}_{1} & =60 \mathrm{Kg} / \mathrm{m}, \\
\mathrm{E}_{1} & =2.1 \times 10^{5} \mathrm{Mpa}, \\
\mathrm{I}_{1} & =3.217 \times 10^{-5} \mathrm{~m}^{4}, \\
\mathrm{~m}_{2} & =1275 \mathrm{Kg} / \mathrm{m}, \\
\mathrm{E}_{2} & =3.55 \times 10^{4} \mathrm{Mpa}, \\
\mathrm{I}_{2} & =1.7 \times 10^{-3} \mathrm{~m}^{4}, \\
\mathrm{~m}_{3} & =1401.25 \mathrm{Kg} / \mathrm{m}, \\
\mathrm{E}_{3} & =3.0 \times 10^{4} \mathrm{Mpa}, \\
\mathrm{I}_{3} & =1.686 \times 10^{-3} \mathrm{~m}^{4}, \\
\mathrm{~m}_{4} & =18300 \mathrm{Kg} / \mathrm{m}, \\
\mathrm{E}_{4} & =3.45 \times 10^{4} \mathrm{Mpa} \\
\mathrm{I}_{4} & =10.95 \mathrm{~m}^{4}, \\
\mathrm{~L}_{1} & =\mathrm{L}_{2}=\mathrm{L} \mathrm{L}_{3}=\mathrm{L}_{4}=32 \mathrm{~m}, \\
\mathrm{k}_{1} & =60 \mathrm{MN} / \mathrm{m}^{2}, \\
\mathrm{k}_{2} & =900 \mathrm{MN} / \mathrm{m}^{2}, \\
\mathrm{p}_{1} & =1375 \mathrm{MN} / \mathrm{m}^{2}, \\
& =85 \mathrm{KN}
\end{aligned}
$$

Similar to the double-beam system's analysis, the timehistory responses for the mid-span displacements of the 


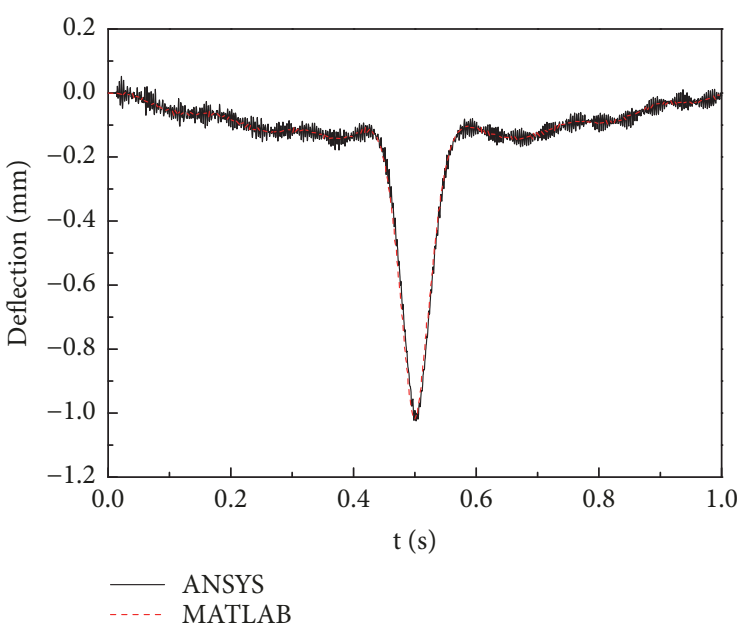

(a)

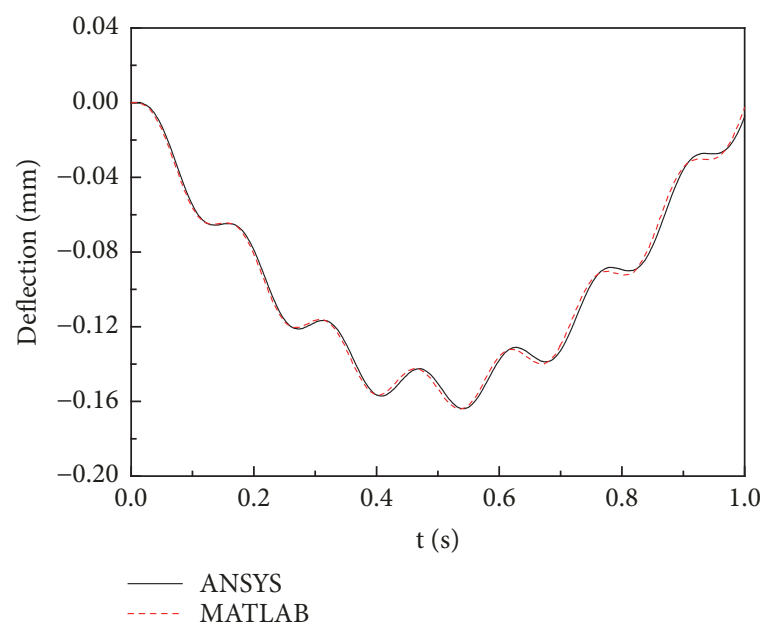

(b)

Figure 3: Mid-span deflection time-history for double simply supported rail-bridge system with load moving speed v= $32 \mathrm{~m} / \mathrm{s}$ : (a) first beam; (b) second beam.

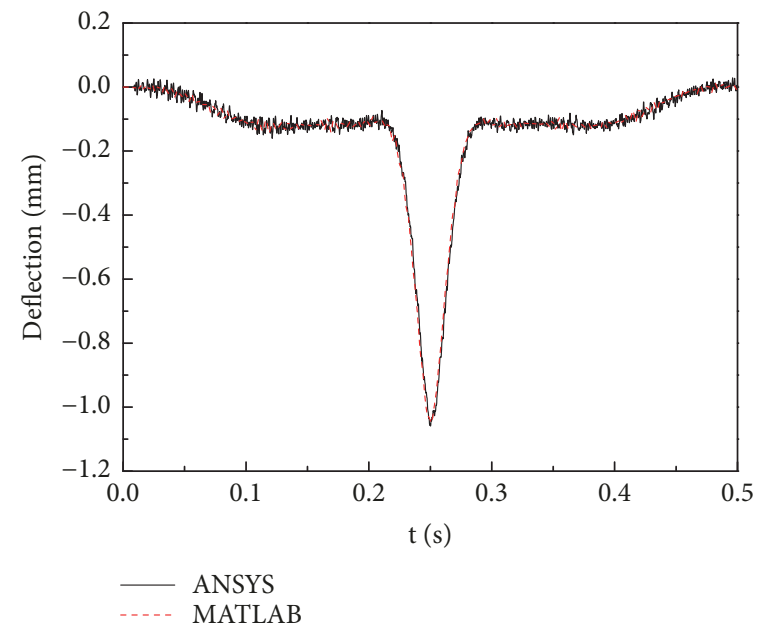

(a)

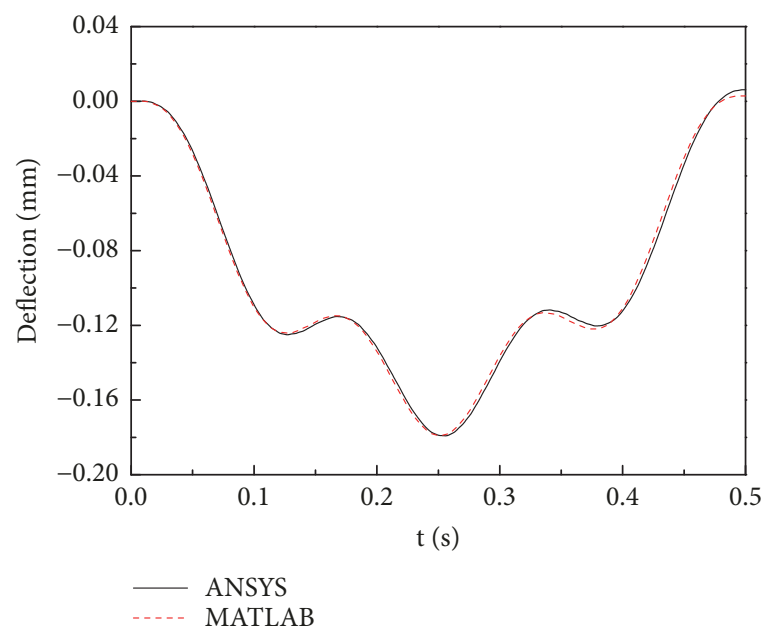

(b)

FIGURE 4: Mid-span deflection time-history for double simply supported rail-bridge system with load moving speed $\mathrm{v}=64 \mathrm{~m} / \mathrm{s}$ : (a) first beam; (b) second beam.

quadruple simply supported beam system subjected to external load with different moving speeds $(32 \mathrm{~m} / \mathrm{s}$ and $64 \mathrm{~m} / \mathrm{s}$ ) were calculated. The comparisons between the theoretically calculated results and the ANSYS finite element numerical calculation are shown in Figures 5 and 6. The results also show that the theoretical results are consistent with the results obtained from the ANSYS finite element numerical calculation, thus validating and rationalizing this theoretical analysis model in an effective manner.

3.2. Analysis of Maximum Deflection-Loading Speed for MidSpan of Double Simply Supported Beam. Figure 7 shows the maximum dynamic deflection for the mid-span of double simply supported rail-bridge system at different load moving speeds. With the increase in load moving speeds, the effect of speed on the dynamic response of the double simply supported rail-bridge beam system shows a nonlinear relationship; a sine curve was observed instead of increasing with the increase of speed linearly. The maximum midspan deflection for the first simply supported beam shows the variation of sine curve around the amplitude of 1.02 $\mathrm{mm}$. Besides, with the increase of speed, the period and amplitude of sine curve also increased. The maximum midspan deflection for the second simply supported beam also shows the variation of sine curve, but unlike the first beam, the mid-span deflection for this beam shows an overall increasing trend with the increase of speeds.

Due to the very low moment of inertia of the first beam compared to the second beam, the first beam shows hierarchical oscillations while the secondary beam does not show any local oscillations, and the mid-span deflection dynamic response of the first beam is insensitive to the 


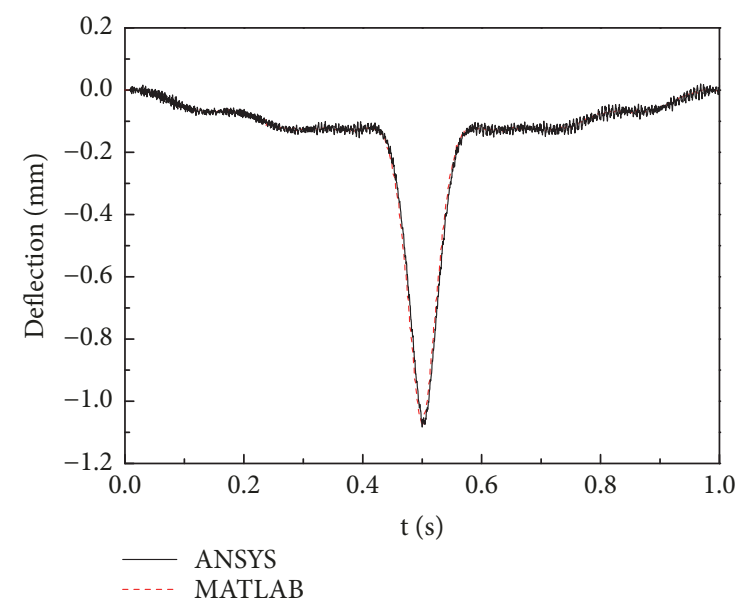

(a)

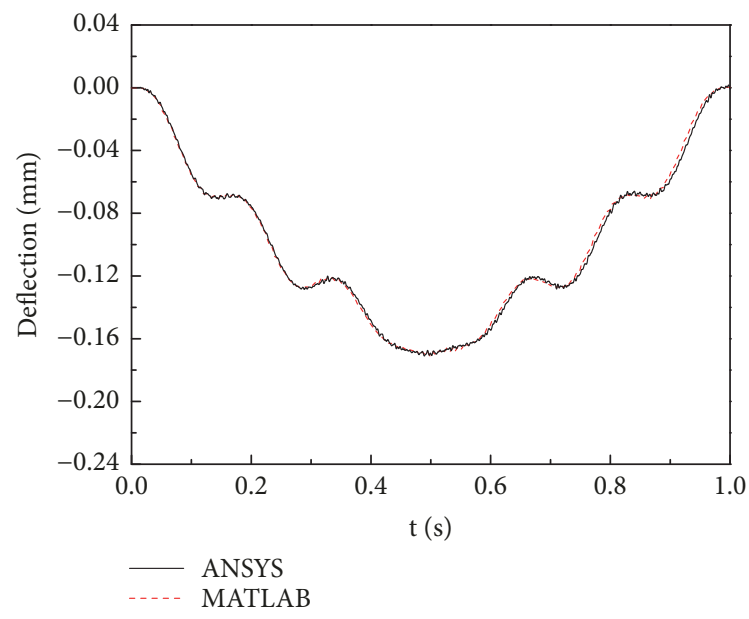

(c)

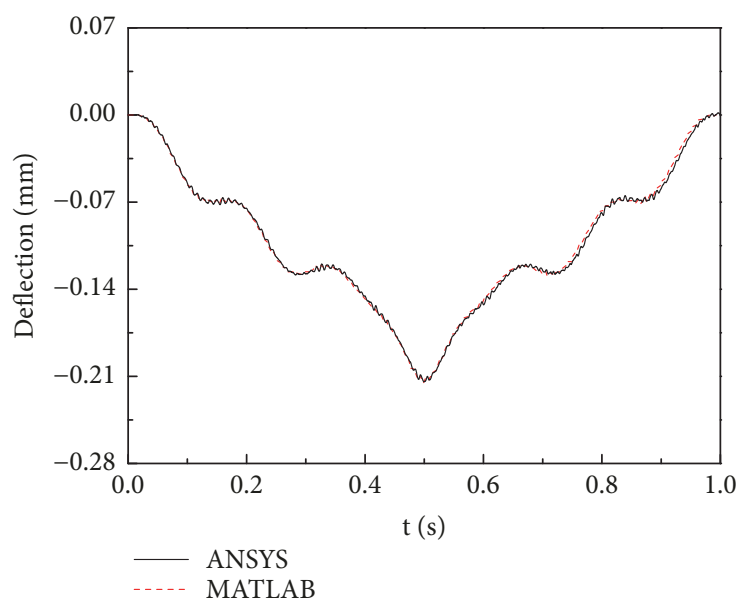

(b)

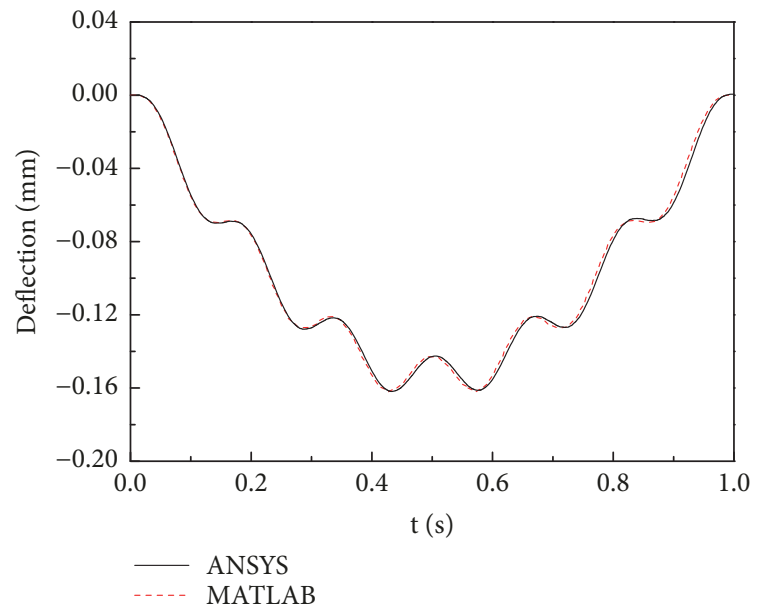

(d)

FIGURE 5: Mid-span deflection time-history for quadruple simply supported beam system with load moving speed v = $32 \mathrm{~m} / \mathrm{s}$ : (a) first beam; (b) second beam; (c) third beam; (d) fourth beam.

speed. Relationship between maximum deflection and loading speed for mid-span of double simply supported beam with a higher $I_{1}$ value is shown in Figures 8-9. The results show that the local oscillation of the first beam's mid-span maximum deflection reduced significantly when the moment of inertia $I_{1}$ is revalued as $100 \mathrm{I}_{1}$, and there are barely no local oscillations of the first beam's mid-span maximum deflection when the moment of inertia $\mathrm{I}_{1}$ is taken as $10^{5} \mathrm{I}_{1}$.

Moreover, the speeds at which the mid-span deflection for the double beams reaches the peak value are the same, with the appearance of multiple points of resonance (wave crest) and points of cancellation (wave trough), as shown in Table 1.

Figures 10 and 11 show the contrast of mid-span deflection responses of the double simply supported rail-bridge beam system under different resonances and cancellation speeds.

Table 1 and Figures 10-11 show that, with the increase in resonance speeds, the time-history curves of mid-span deflection dynamic response of the first beam are consistent, while the local oscillation of mid-span deflection timehistory curves of the second beam significantly reduced, the vibration period becomes longer, and the mid-span dynamic response reaches the amplitude when the moving loads act near the mid-span of double rail-bridge system. With the increase in cancellation speeds, the time-history curves of mid-span deflection dynamic response of the first beam are consistent, and when the mid-span deflection dynamic response of the second beam reaches the amplitude, the distance between the moving-load position and mid-span increases. When the load moving speed is $88.1 \mathrm{~m} / \mathrm{s}$, the midspan dynamic deflection response of the second beam reaches the amplitude while the moving loads are on the $1 / 3$ and $2 / 3$ positions of the beam.

3.3. Analysis of Parameter Influence of Double Simply Supported Rail-Bridge System. Based on the analysis in the above section, further study was conducted regarding the effect of interlayer spring stiffness, beam masses, and flexural rigidities on the dynamic responses of the double simply supported rail-bridge system in this section. The moving speed of loads $\mathrm{v}=100 \mathrm{~m} / \mathrm{s}$ was taken as the example to study the effect of variation of three parameters. 


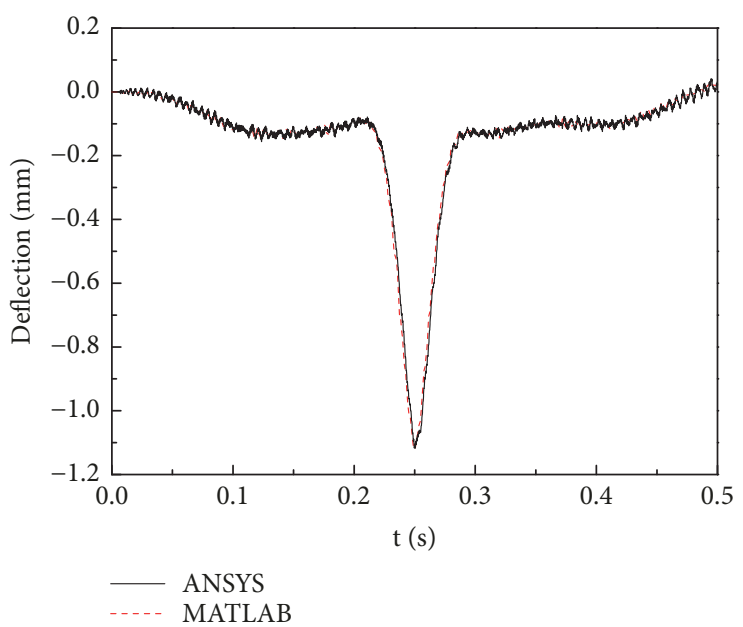

(a)

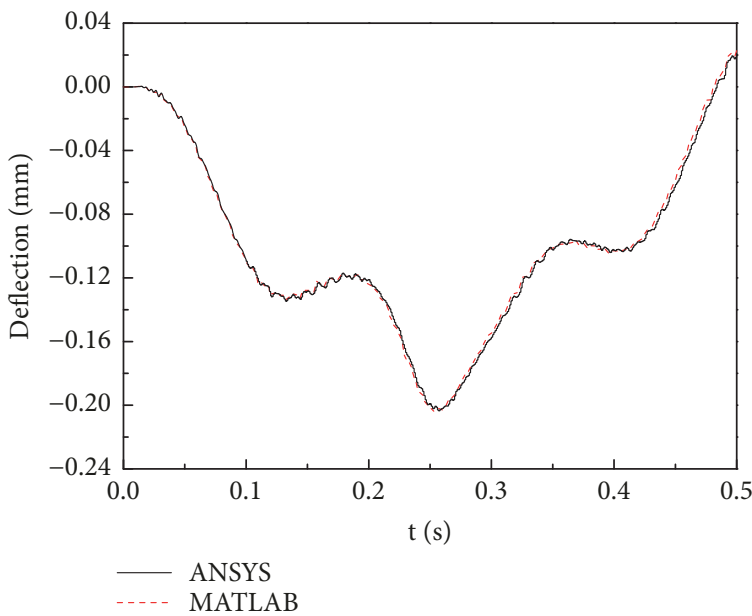

(c)

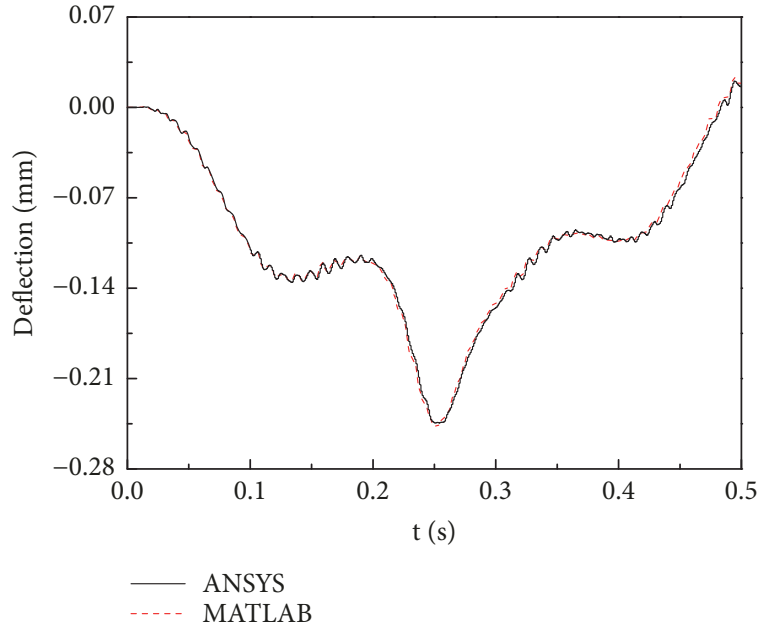

(b)

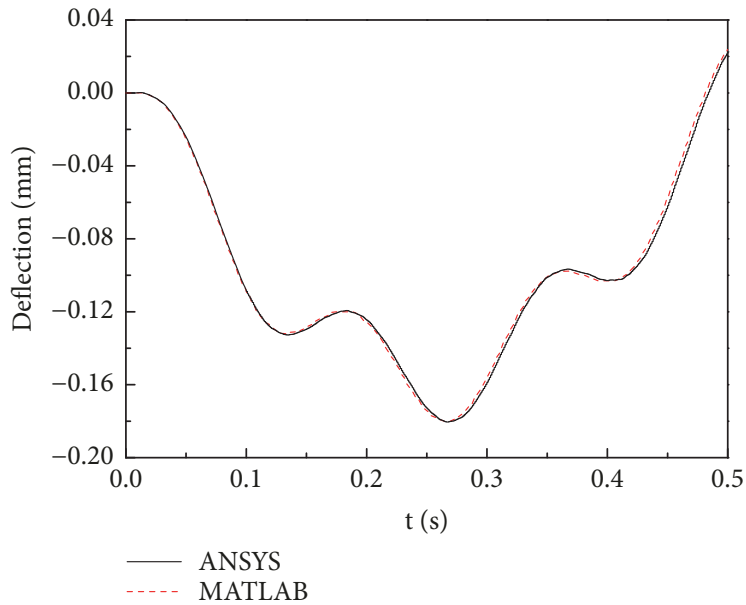

(d)

Figure 6: Mid-span deflection time-history for quadruple simply supported beam system with load moving speed v = $64 \mathrm{~m} / \mathrm{s}$ : (a) first beam; (b) second beam; (c) third beam; (d) fourth beam.

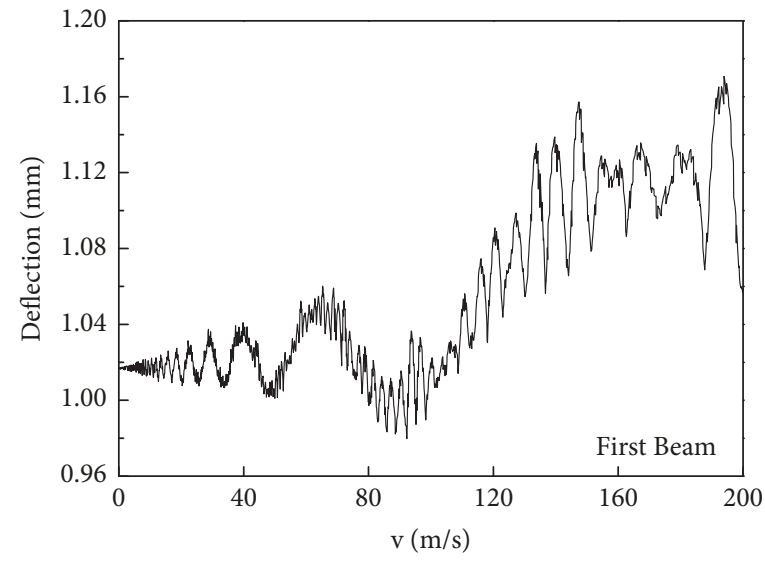

(a)

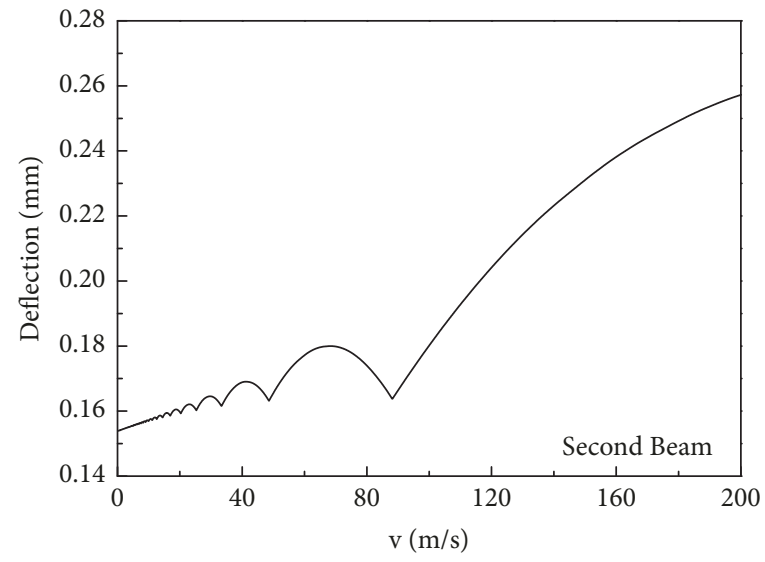

(b)

Figure 7: Relationship between maximum deflection and loading speed for mid-span of double simply supported beam: (a) first beam; (b) second beam. 


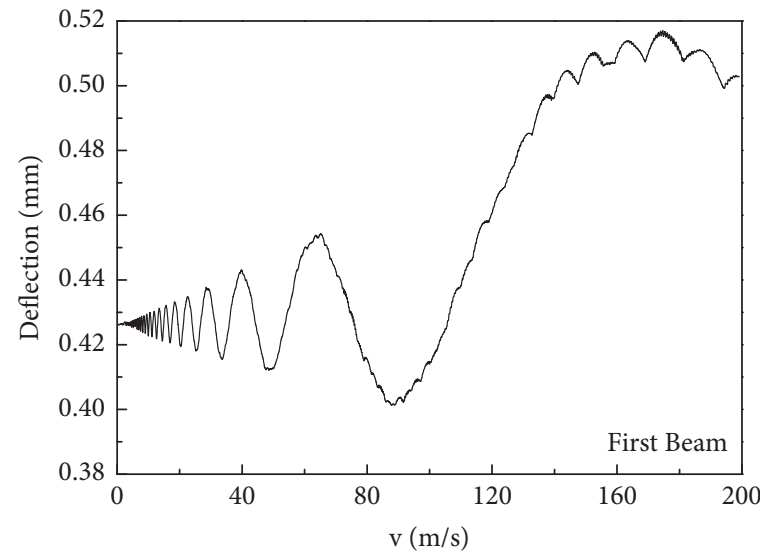

(a)

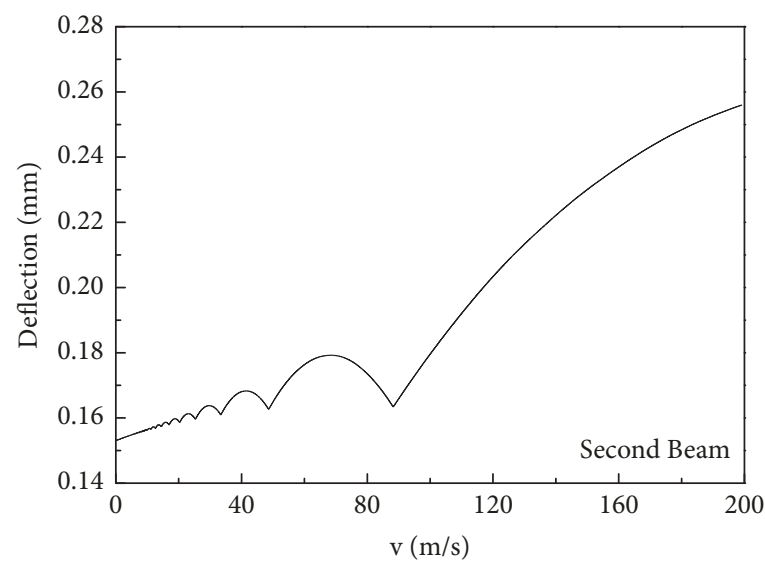

(b)

FiguRE 8: Relationship between maximum deflection and loading speed for mid-span of double simply supported beam with first beam's moment of inertia taking as $100 \mathrm{I}_{1}$ : (a) first beam; (b) second beam.

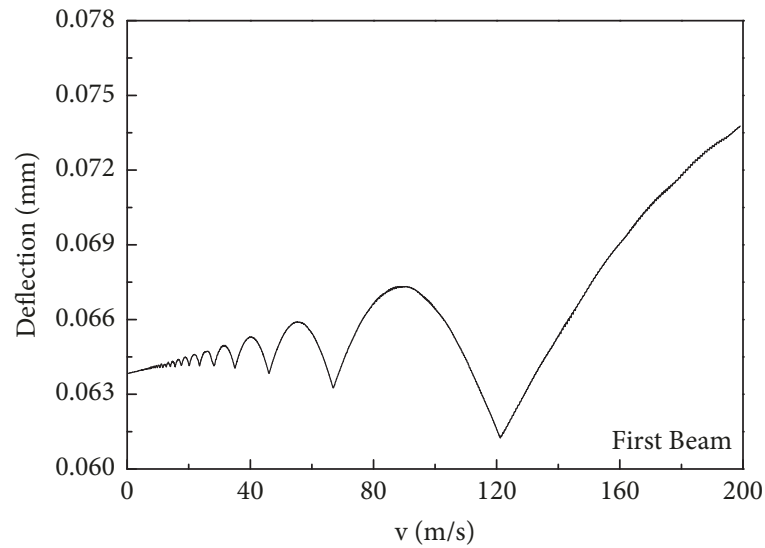

(a)

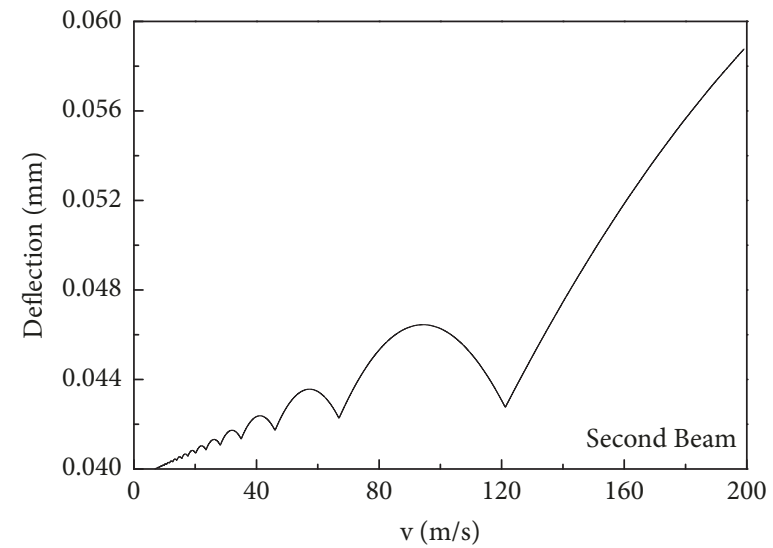

(b)

FIGURE 9: Relationship between maximum deflection and loading speed for mid-span of double simply supported beam with first beam's moment of inertia taking as $10^{5} \mathrm{I}_{1}$ : (a) first beam; (b) second beam.

TABLE 1: Relationship between resonance (cancellation) speed and amplitude.

\begin{tabular}{|c|c|c|c|c|c|}
\hline $\begin{array}{l}\text { Speed at the wave } \\
\text { crest }(\mathrm{m} / \mathrm{s})\end{array}$ & $\begin{array}{l}\text { Amplitude at the } \\
\text { mid-span of first } \\
\text { beam }(\mathrm{mm})\end{array}$ & $\begin{array}{l}\text { Amplitude at the } \\
\text { mid-span of } \\
\text { second beam }(\mathrm{mm})\end{array}$ & $\begin{array}{c}\text { Speed at the wave } \\
\text { trough }(\mathrm{m} / \mathrm{s})\end{array}$ & $\begin{array}{l}\text { Amplitude at the } \\
\text { mid-span of first } \\
\text { beam }(\mathrm{mm})\end{array}$ & $\begin{array}{l}\text { Amplitude at the } \\
\text { mid-span of } \\
\text { second beam }(\mathrm{mm})\end{array}$ \\
\hline 18.9 & 1.024 & 0.161 & 20.4 & 1.009 & 0.159 \\
\hline 23.2 & 1.025 & 0.162 & 25.3 & 1.015 & 0.160 \\
\hline 29.9 & 1.027 & 0.165 & 33.4 & 1.011 & 0.162 \\
\hline 41.1 & 1.039 & 0.169 & 48.7 & 1.004 & 0.163 \\
\hline 68.7 & 1.058 & 0.180 & 88.1 & 0.996 & 0.164 \\
\hline
\end{tabular}

Figure 12 show that interlayer stiffness variation has a greater effect on the dynamic response of the first simply supported beam, and the mid-span dynamic deflection amplitude of the first simply supported beam decreased with the increase in interlayer stiffness, while the interlayer stiffness has a negligible effect on the mid-span dynamic time-history of the second simply supported beam. The reason is that, in the double simply supported rail-bridge system, the differences in the stiffness of the first and second beams are large, the flexural rigidity of the first beam is 


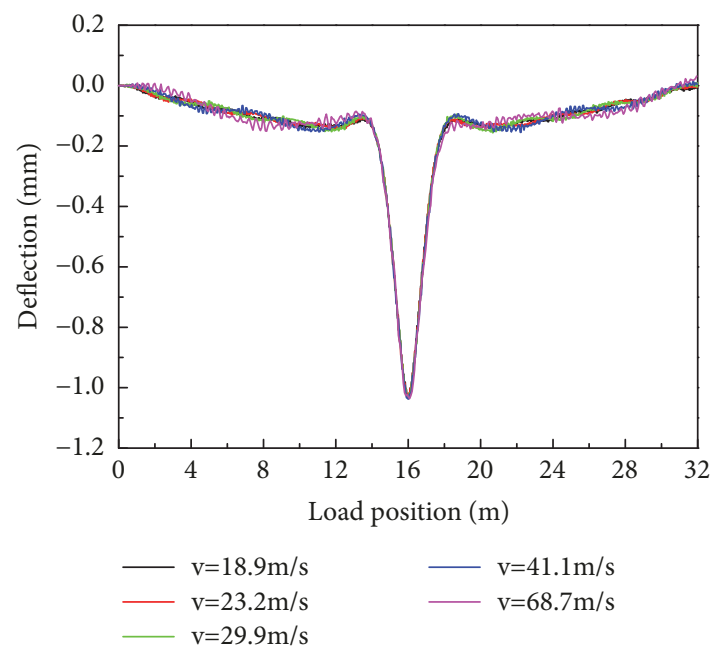

(a)

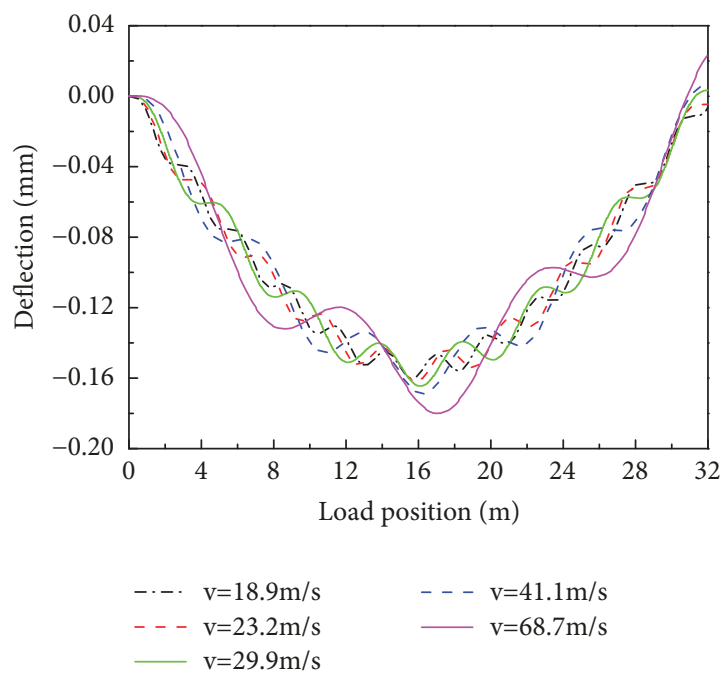

(b)

FIGURE 10: Mid-span deflection time-history for double simply supported rail-bridge system under resonance condition: (a) first beam; (b) second beam.

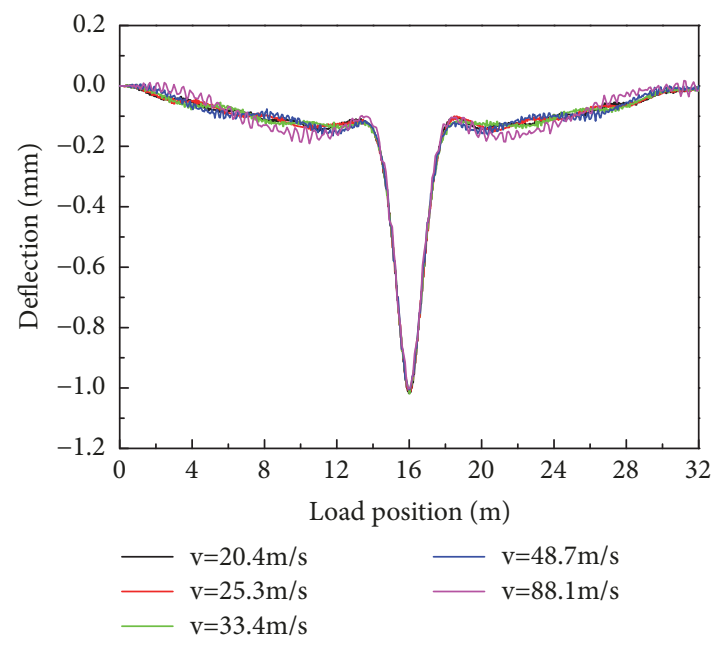

(a)

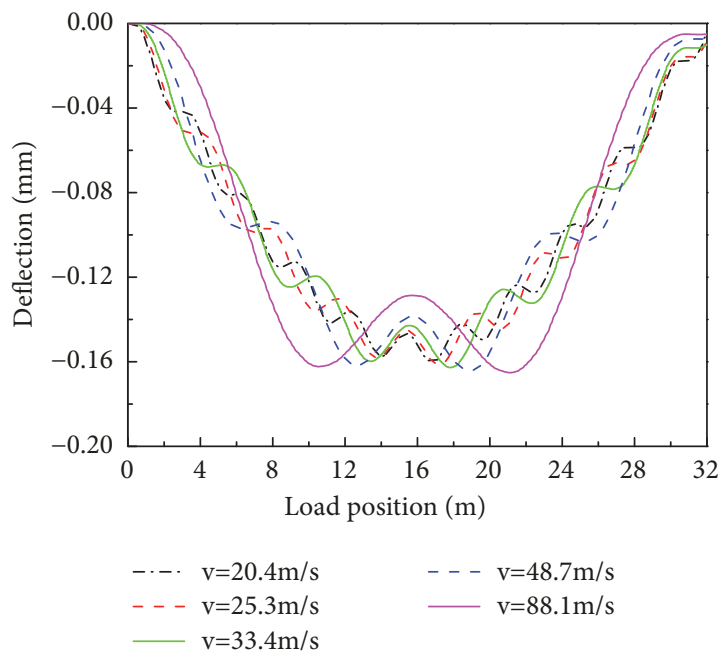

(b)

FIGURE 11: Mid-span deflection time-history for the double simply supported rail-bridge system under cancellation condition: (a) first beam; (b) second beam.

much smaller than that of the second beam, and the bending resistance of the second beam plays a leading role in the bending resistance of the entire system.

Figures 13 and 14 show the effects of mass variation per unit length of the first and second beams on midspan deflection time-history for double simply supported rail-bridge system, respectively. Figure 13 shows that, under different masses of the first beam, the time-history curves of mid-span deflection dynamic response for the two simply supported beams are consistent. Therefore, the effect of mass variation of the first simply supported beam on the mid-span deflection dynamic response of the double-beam system can be neglected. Figure 14 shows that the mass variation of the second simply supported beam has a significant effect on the mid-span deflection dynamic response of both beams, when the mass per unit length of the second simply supported beam increases to four times of the original mass, the amplitudes of mid-span deflection dynamic response of the first and second simply supported beams both increase significantly, with the growth rate reaching up to $10 \%$ and $45 \%$, respectively.

Figures 15 and 16 show the effect of flexural rigidity variations of the first and second simply supported beams on the mid-span deflection time-history for double simply supported rail-bridge system. Figure 15 shows that the midspan dynamic deflection amplitude of the first simply supported beam significantly decreased with the increase in the stiffness of this beam, while the stiffness of the first beam has a smaller effect on the mid-span dynamic deflection 


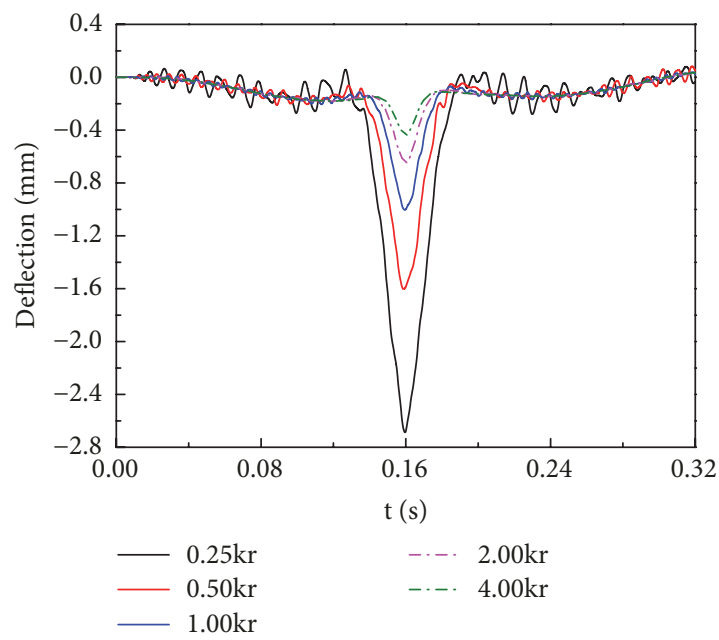

(a)

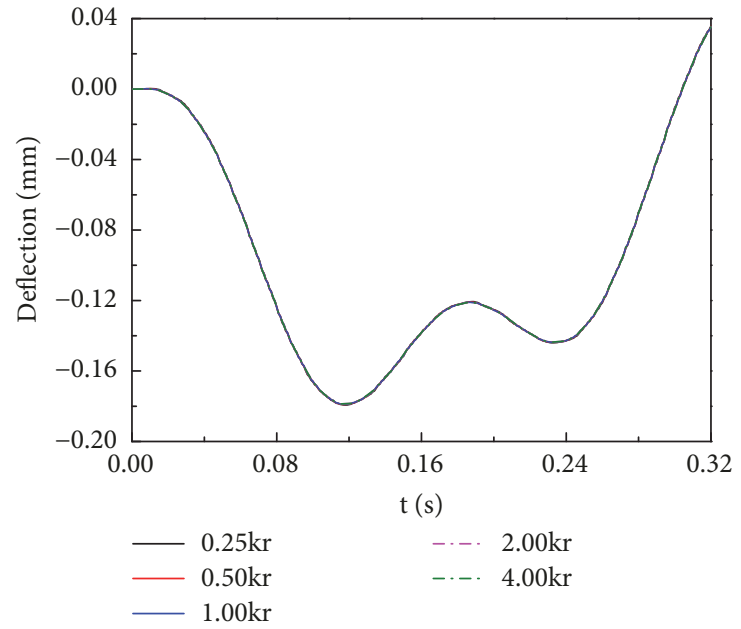

(b)

FIGURE 12: Comparison diagram of mid-span deflection time-history for the double simply supported rail-bridge system under different interlayer stiffness: (a) first beam; (b) second beam.

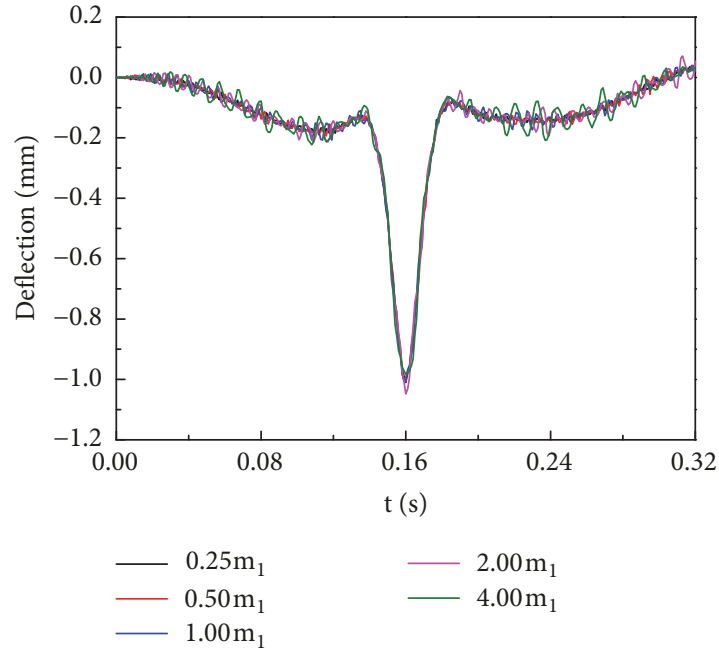

(a)

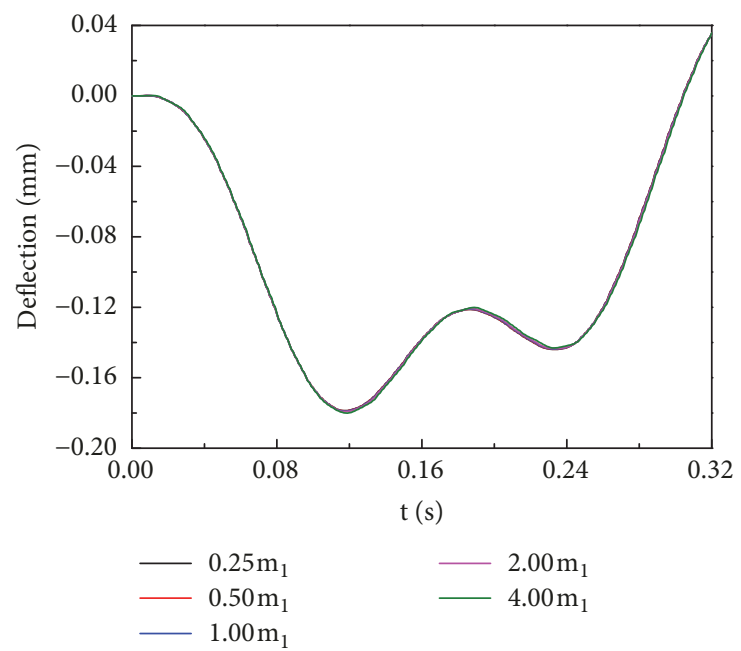

(b)

Figure 13: Comparison diagram of mid-span deflection time-history for double simply supported rail-bridge system under different masses of first beam: (a) first beam; (b) second beam.

amplitude of the second simply supported beam. Under different stiffness of the first beam, the mid-span deflection dynamic time-history curves for the second simply supported beam are consistent. Figure 16 shows that the flexural rigidity variations of the second simply supported beam have a significant effect on the mid-span deflection dynamic response of double simply supported rail-bridge system. In addition, the mid-span deflection dynamic response amplitudes of both beams significantly increased with the decrease in the flexural stiffness of second beam. In practical applications, the dynamic response of the rail-bridge system in high-speed railways can be decreased by moderately decreasing the mass of the second beam and increasing the flexural stiffness of both simply supported beams.

\section{Conclusions}

In this study, a dynamic analysis model was established for a multiple simply supported beam system subjected to moving loads; in combination of finite sin-Fourier transform and numerical Laplace transform based on Durbin transform, an analytical calculation method was developed for the spatial displacement time-domain response of a multiple simply supported beam system. The following conclusions are drawn by comparing the examples and ANSYS finite element numerical computation method:

(1) A simply supported rail-bridge system of high-speed railways with a span of $32 \mathrm{~m}$ in China was taken as the example, and the theoretically calculated results were compared with the results obtained from ANSYS finite element 


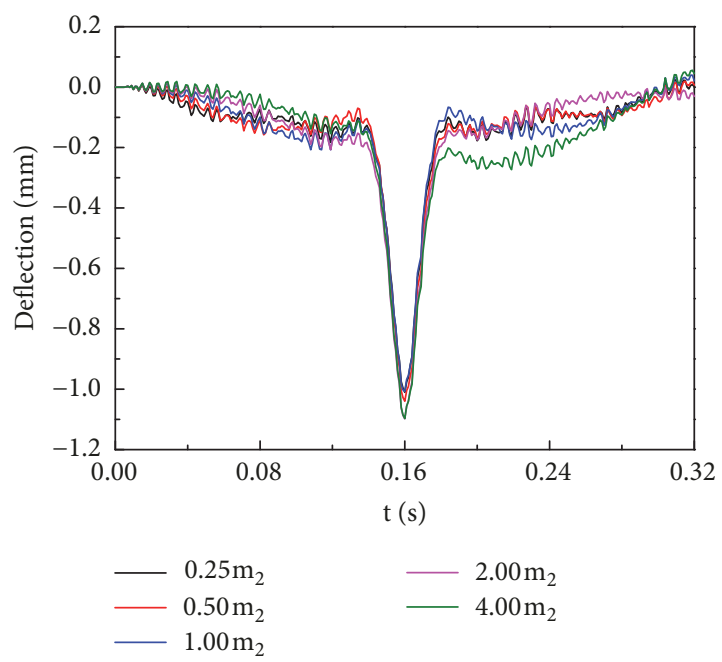

(a)

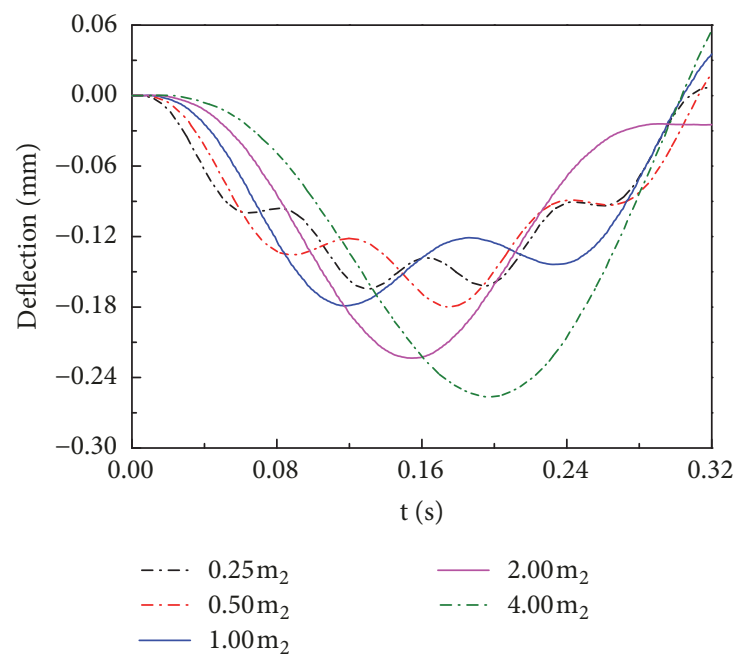

(b)

FIGURE 14: Comparison diagram of mid-span deflection time-history for double simply supported rail-bridge system under different masses of second beam: (a) first beam; (b) second beam.

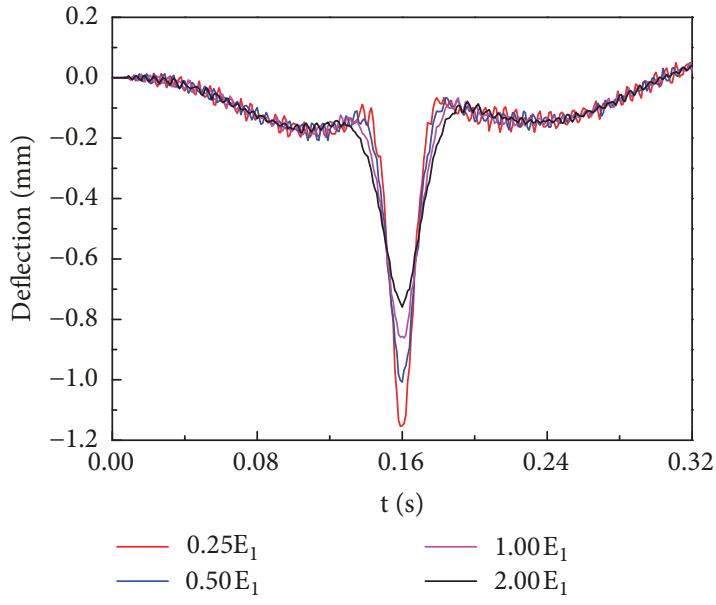

(a)

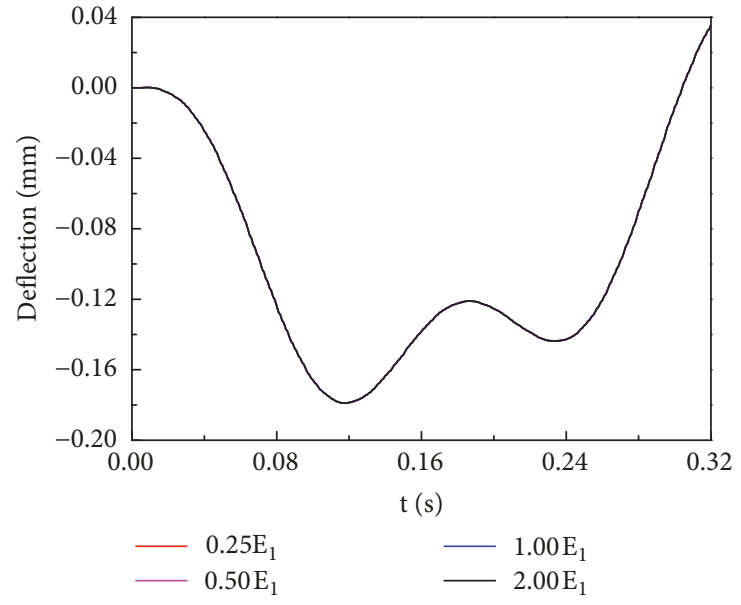

(b)

FIGURE 15: Comparison diagram of mid-span deflection time-history for double simply supported rail-bridge system under different stiffness of first beam: (a) first beam; (b) second beam.

numerical calculation, validating the analytical calculation method reported in this paper.

(2) The effect of load moving speed on the dynamic response of a double simply supported rail-bridge system of high-speed railways subjected to moving loads was evaluated. The results indicate that the double simply supported railbridge system has multiple points of resonance and cancellation, which should be paid attention in engineering.

(3) For a typical double simply supported rail-bridge system of high-speed railway in China, because of a large difference in the flexural rigidity of the first and second beams, the variation in interlayer stiffness mainly affects the dynamic response of the first simply supported beam, exhibiting a positive correlation. When the mass and flexural stiffness parameters of first simply supported beam vary, they mainly affect the dynamic response of this layer of simply supported beam but slightly affect the dynamic response of second simply supported beam. The variation in the parameters of second simply supported beam has a greater effect on the double simply supported beam system, and a decrease in the mass of this layer of simply supported beam and an increase in the flexural rigidity of this beam can both decrease the dynamic response of the double simply supported rail-bridge system.

\section{Data Availability}

The data used to support the findings of this study are included within the article. 


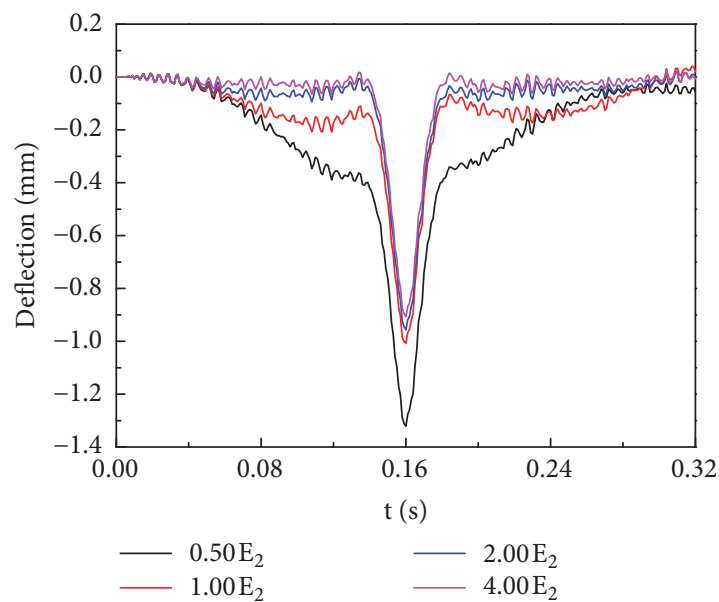

(a)

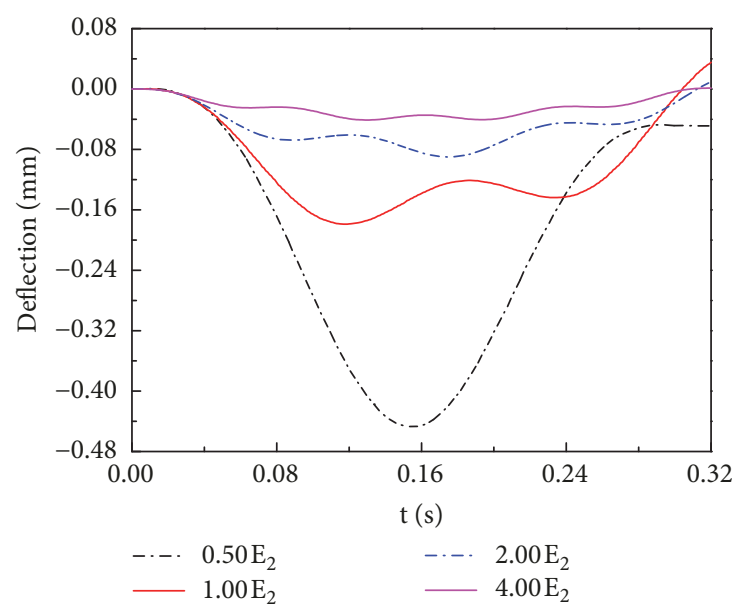

(b)

FiguRE 16: Comparison diagram of mid-span deflection time-history for double simply supported rail-bridge system under different stiffness of second beam: (a) first beam; (b) second beam.

\section{Conflicts of Interest}

The authors declare that they have no conflicts of interest.

\section{Acknowledgments}

The research described in this paper was financially supported by the National Natural Science Foundation of China (51708630).

\section{References}

[1] H. Ouyang, "Moving-load dynamic problems: a tutorial (with a brief overview)," Mechanical Systems and Signal Processing, vol. 25, no. 6, pp. 2039-2060, 2011.

[2] D. G. Duffy, "The response of an infinite railroad track to a moving, vibrating mass," Journal of Applied Mechanics, vol. 57, no. 1, pp. 66-73, 1990.

[3] L. Frýba, Vibration of solids and structures under moving loads, Springer Science \& Business Media, 2013.

[4] G. Michaltsos, D. Sophianopoulos, and A. N. Kounadis, "The effect of a moving mass and other parameters on the dynamic response of a simply supported beam," Journal of Sound and Vibration, vol. 191, no. 3, pp. 357-362, 1996.

[5] P. Museros, E. Moliner, and M. D. Martínez-Rodrigo, "Free vibrations of simply-supported beam bridges under moving loads: Maximum resonance, cancellation and resonant vertical acceleration," Journal of Sound and Vibration, vol. 332, no. 2, pp. 326-345, 2013.

[6] P. Śniady, "Dynamic response of a Timoshenko beam to a moving force," Journal of Applied Mechanics, vol. 75, no. 2, Article ID 024503, 2008.

[7] A. Mamandi and M. H. Kargarnovin, "Nonlinear dynamic analysis of an inclined Timoshenko beam subjected to a moving mass/force with beam's weight included," Shock and Vibration, vol. 18, no. 6, pp. 875-891, 2011.

[8] K. Y. Lee and A. A. Renshaw, "Solution of the moving mass problem using complex eigenfunction expansions," Journal of Applied Mechanics, vol. 67, no. 4, pp. 823-827, 2000.
[9] U. Lee, "Separation between the flexible structure and the moving mass sliding on it," Journal of Sound and Vibration, vol. 209, no. 5, pp. 867-877, 1998.

[10] S. A. Eftekhari and A. A. Jafari, "Coupling ritz method and triangular quadrature rule for moving mass problem," Journal of Applied Mechanics, vol. 79, no. 2, 2012.

[11] M. Dublin and H. R. Friedrich, "Forced responses of two elastic beams interconnected by spring-damper systems," Journal of the Aeronautical Sciences, vol. 23, pp. 824-829, 1956.

[12] J. M. Seelig and W. H. Hoppmann, "Impact on an elastically connected double-beam system," Journal of Applied Mechanics, vol. 31, pp. 621-626, 1964.

[13] P. G. Kessel, "Resonances Excited in an Elastically Connected Double-Beam System by a Cyclic Moving Load," The Journal of the Acoustical Society of America, vol. 40, no. 3, pp. 684-687, 1966.

[14] S. Chonan, "Dynamical behaviours of elastically connected double-beam systems subjected to an impulsive load," Bulletin of JSME, vol. 19, no. 132, pp. 595-603, 1976.

[15] H. V. Vu, A. M. Ordóñez, and B. H. Karnopp, "Vibration of a double-beam system," Journal of Sound and Vibration, vol. 229, no. 4, pp. 807-822, 2000.

[16] H. J. Xu, Z. H. Ding, Z. R. Lu, and J. K. Liu, "Structural Damage Detection Using a Modified Artificial Bee Colony Algorithm," CMES-Computer Modeling in Engineering \& Sciences, vol. 111, pp. 335-355, 2016.

[17] Z. Oniszczuk, "Free transverse vibrations of elastically connected simply supported double-beam complex system," Journal of Sound and Vibration, vol. 232, no. 2, pp. 387-403, 2000.

[18] Z. Oniszczuk, "Forced transverse vibrations of an elastically connected complex simply supported double-beam system," Journal of Sound and Vibration, vol. 264, no. 2, pp. 273-286, 2003.

[19] Y. Q. Zhang, Y. Lu, S. L. Wang, and X. Liu, "Vibration and buckling of a double-beam system under compressive axial loading," Journal of Sound and Vibration, vol. 318, no. 1-2, pp. 341-352, 2008.

[20] V. Stojanović and P. Kozić, "Forced transverse vibration of Rayleigh and Timoshenko double-beam system with effect of 
compressive axial load," International Journal of Mechanical Sciences, vol. 60, no. 1, pp. 59-71, 2012.

[21] A. Palmeri and S. Adhikari, "A Galerkin-type state-space approach for transverse vibrations of slender double-beam systems with viscoelastic inner layer," Journal of Sound and Vibration, vol. 330, no. 26, pp. 6372-6386, 2011.

[22] Z. Zhang, X. Huang, Z. Zhang, and H. Hua, "On the transverse vibration of Timoshenko double-beam systems coupled with various discontinuities," International Journal of Mechanical Sciences, vol. 89, pp. 222-241, 2014.

[23] Y. X. Li, Z. J. Hu, and L. Z. Sun, "Dynamical behavior of a double-beam system interconnected by a viscoelastic layer," International Journal of Mechanical Sciences, vol. 105, pp. 291303, 2016.

[24] M. Abu-Hilal, "Dynamic response of a double Euler-Bernoulli beam due to a moving constant load," Journal of Sound and Vibration, vol. 297, no. 3-5, pp. 477-491, 2006.

[25] Y. Wu and Y. Gao, "Analytical Solutions for Simply Supported Viscously Damped Double-Beam System under Moving Harmonic Loads," Journal of Engineering Mechanics, vol. 141, no. 7, p. 04015004, 2015.

[26] Y.-H. Chen and Z.-M. Shiu, "Resonant curves of an elevated railway to harmonic moving loads," International Journal of Structural Stability and Dynamics, vol. 4, no. 2, pp. 237-257, 2004.

[27] Y.-H. Chen, Y.-H. Huang, and C.-T. Shih, "Response of an infinite tomoshenko beam on a viscoelastic foundation to a harmonic moving load," Journal of Sound and Vibration, vol. 241, no. 5, pp. 809-824, 2001.

[28] M. F. M. Hussein and H. E. M. Hunt, "Modelling of floating-slab tracks with continuous slabs under oscillating moving loads," Journal of Sound and Vibration, vol. 297, no. 1-2, pp. 37-54, 2006.

[29] H. P. Wang, J. Li, and K. Zhang, "Vibration analysis of the maglev guideway with the moving load," Journal of Sound and Vibration, vol. 305, no. 4-5, pp. 621-640, 2007.

[30] V. Stojanović and M. Petković, "Moment Lyapunov exponents and stochastic stability of a three-dimensional system on elastic foundation using a perturbation approach," Journal of Applied Mechanics, vol. 80, no. 5, 2013.

[31] L. Jun and H. Hongxing, "Dynamic stiffness vibration analysis of an elastically connected three-beam system," Applied Acoustics, vol. 69, no. 7, pp. 591-600, 2008.

[32] J. Li, Y. Chen, and H. Hua, "Exact dynamic stiffness matrix of a Timoshenko three-beam system," International Journal of Mechanical Sciences, vol. 50, no. 6, pp. 1023-1034, 2008.

[33] S. S. Rao, "Natural vibrations of systems of elastically connected Timoshenko beams ," The Journal of the Acoustical Society of America, vol. 55, no. 6, pp. 1232-1237, 1974.

[34] Q. Mao, "Free vibration analysis of elastically connected multiple-beams by using the Adomian modified decomposition method," Journal of Sound and Vibration, vol. 331, no. 11, pp. 2532-2542, 2012.

[35] V. Stojanović, P. Kozić, and G. Janevski, "Exact closed-form solutions for the natural frequencies and stability of elastically connected multiple beam system using Timoshenko and highorder shear deformation theory," Journal of Sound and Vibration, vol. 332, no. 3, pp. 563-576, 2013.

[36] M. H. Kargarnovin, M. T. Ahmadian, and R.-A. JafariTalookolaei, "Analytical solution for the dynamic analysis of a delaminated composite beam traversed by a moving constant force," Journal of Vibration and Control, vol. 19, no. 10, pp. 15241537, 2013.
[37] A. Ariaei, S. Ziaei-Rad, and M. Ghayour, "Transverse vibration of a multiple-Timoshenko beam system with intermediate elastic connections due to a moving load," Archive of Applied Mechanics, vol. 81, no. 3, pp. 263-281, 2011.

[38] Y. Povstenko and J. Klekot, "The Dirichlet problem for the time-fractional advection-diffusion equation in a line segment," Boundary Value Problems, Paper No. 89, 8 pages, 2016.

[39] F. Durbin, "Numerical inversion of Laplace transforms: an efficient improvement to Dubner and Abate's method," The Computer Journal, vol. 17, pp. 371-376, 1974. 


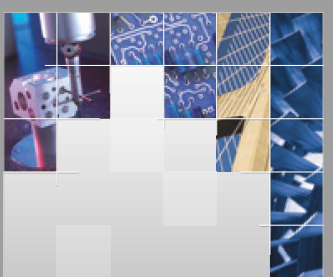

\section{Enfincering}
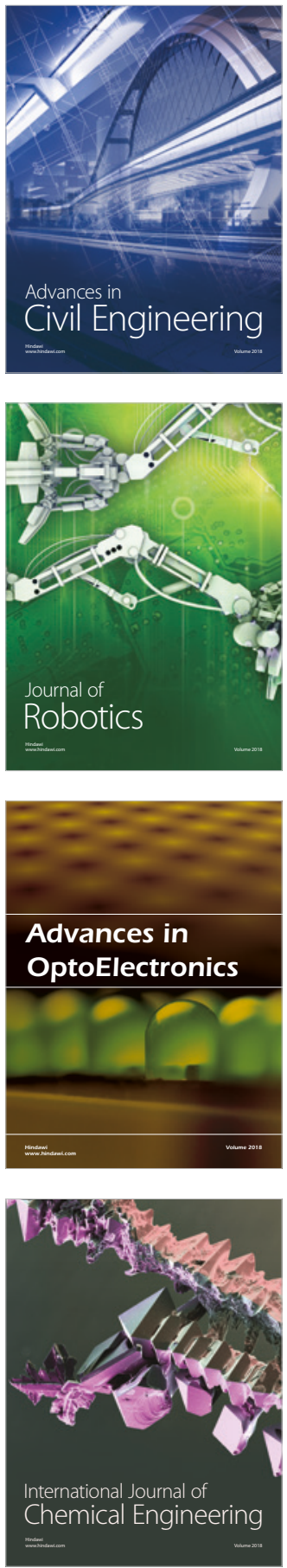

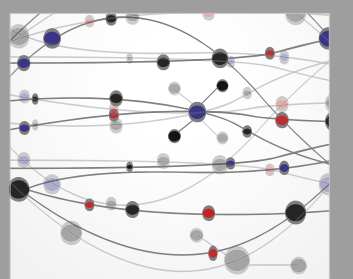

\section{Rotating \\ Machinery}

The Scientific World Journal

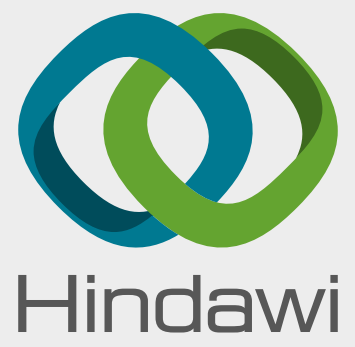

Submit your manuscripts at

www.hindawi.com
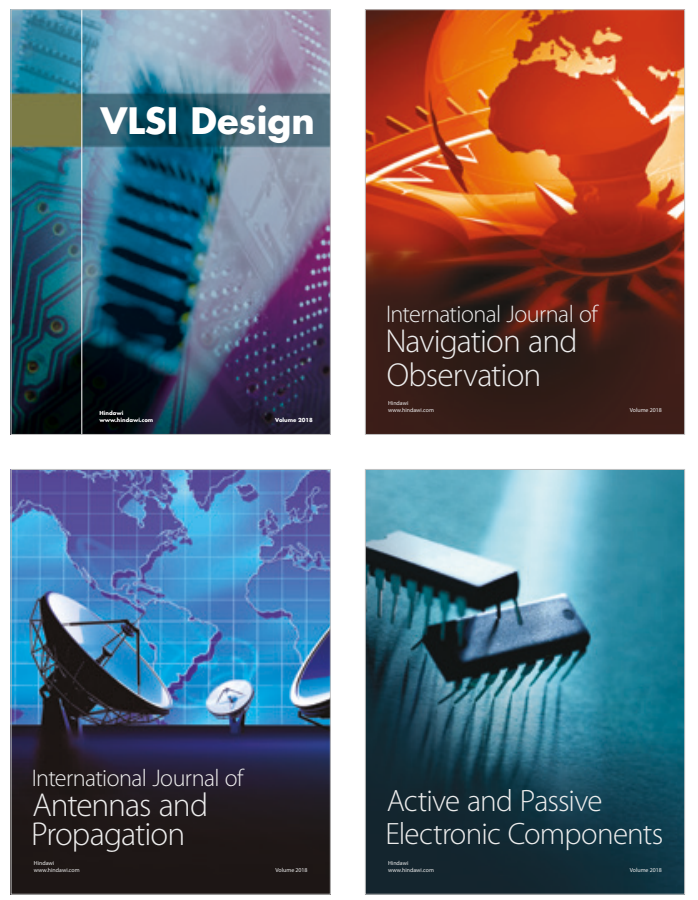
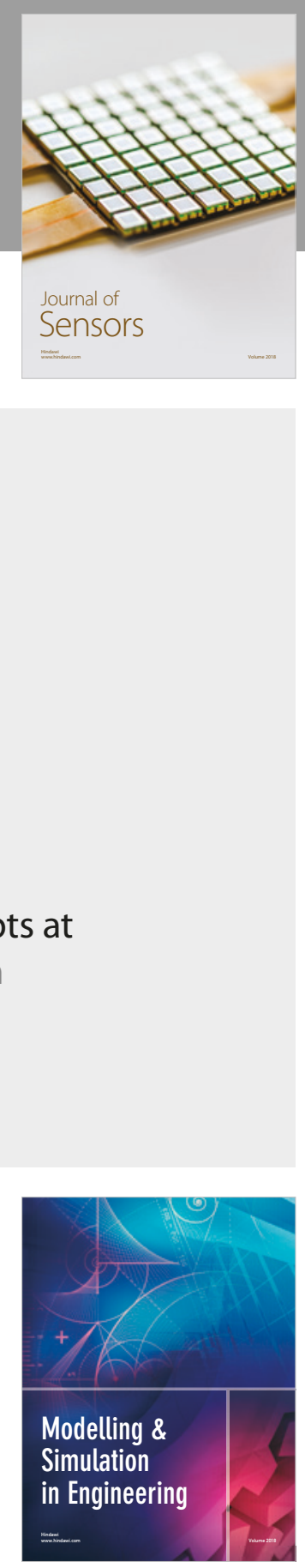

\section{Advances \\ Multimedia}
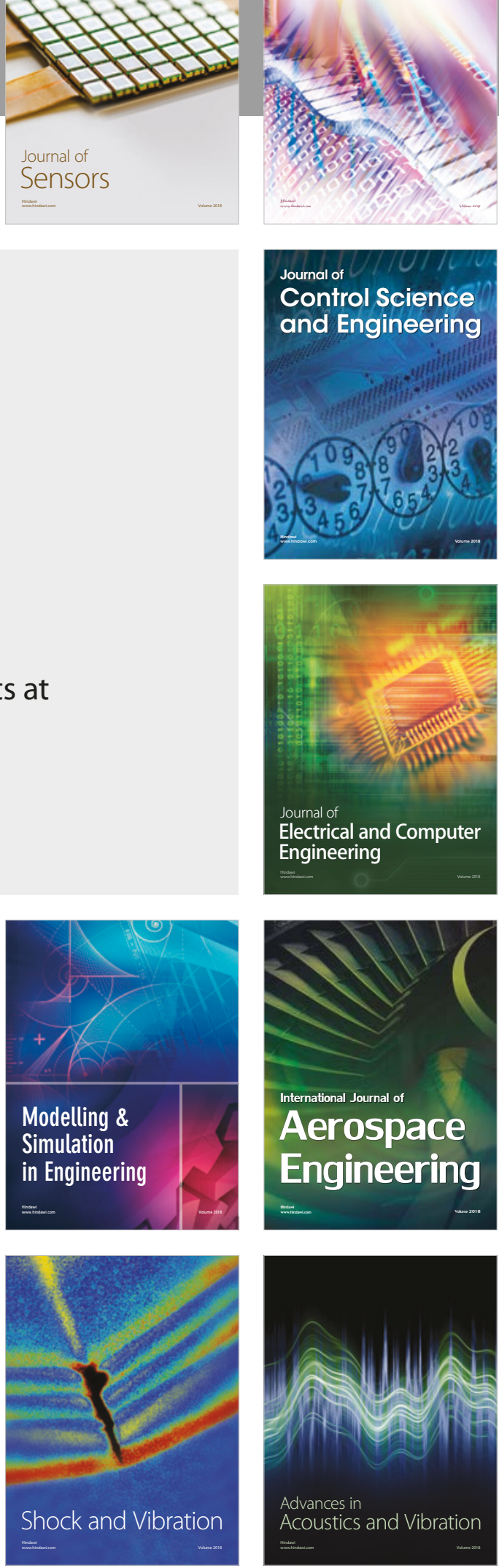